\title{
Adoption and Perceived Usefulness of Social Media by Pre-service Teachers in Nigeria
}

\author{
https://doi.org/10.3991/ijim.v13i06.10299 \\ Ugorji I. Ogbonnaya \\ University of Pretoria, South Africa \\ ugorji.ogbonnaya@up.ac.za
}

\begin{abstract}
Social media networks are fundamentally changing the way we socialize, communicate, and perhaps the way students learn. This paper explored the patterns of pre-service teachers' adoption and perceived usefulness of social media. It also explored the relationships between the pre-service teachers' perceived usefulness of the social media in relation to socialisation, communication, and study, and (a) the time they spend on social media, and (b) their social media account subscriptions. The participants were 388 pre-service teachers from one tertiary institution in Nigeria. The social constructivist theory, the Theory of Planned Behaviour and the Technology Acceptance Model were used to underpin the study. The result revealed that Facebook and WhatsApp were the most common social media applications used by the participants and they use the media chiefly for socialising. With respect to the time they spent on social media daily, $310(80 \%)$ spent at least one hour on social media on average daily while 196 (50\%) spent over two hours on average every day. The relationships between social media subscriptions, and perceived usefulness of social media for socialising and for communication, were found to be positive and statistically significant. Similarly, the relationships between the time spent on social media and perceived usefulness of social media for socialising and also for study were found to be positive and statistically significant. The results suggest that the pre-service teachers are adopters of social media and perceive the media useful not only for social activities but also for academic purposes. However, they have not really adopted the social media for academic purposes. The research findings make a compelling case for the incorporation of social media into the teaching and learning context.
\end{abstract}

Keywords-Pre-service teachers, Social Cognitive Theory, Social media, Technology Acceptance Model, Theory of Planned Behaviour

\section{$1 \quad$ Introduction}

There has been phenomenal advancement in information communication technology (ICT) in general and the World Wide Web and mobile technologies in particular over the last two decades. The evolution of the World Wide Web has impacted immensely on human interaction, behaviour and knowledge acquisition. This evolution has created tremendous changes in people's lives. This is evident from the way people 
communicate, the way they access information and of course the way people learn through the use of ICT. Today, internet related technologies such as social media networks, simply called social media, have become the primary means of communication [1], [2] and social interaction [3].

Today, people in different parts of the world can be connected instantaneously. The connection means that individuals can interact and share information as if they were face-to-face. About this issue, it is pointed out that advancement in ICT “... has meant that ICT tools have not only impacted on societies but also on education systems" [4, p. 1610]. In this regard, the availability of technological data has meant that the World Wide Web is readily available and it can be accessed wherever students are. As a consequence, technological data in the classroom has changed "the scope of learning by allowing flexible and instant access to rich digital resources" [5]. This access to rich digital resources means that students with laptops, smart phones, and tablet personal computers (tablets) can connect to online discussions and discourses.

Technologies, such as Web 2.0 for instance, allow for substantial synergy, collaboration and contribution from the members of virtual communities. Users contribute content and participate in sharing, creating, editing and constructing knowledge that reflect the collective abilities of the users [6]. These authors have in fact indicated that the type of learning that these technologies enable is a compelling alternative to the traditional classroom paradigm. Some studies have been conducted on the way students use social media [7], [8] technology acceptance among pre-service teachers [9] and among teachers [10], [11]. However, there is a paucity of studies on social media acceptance of pre-service teachers especially in Africa. As observed by [11], the expanding role of technology in education highlights the significance of understanding technology adoption by both teachers and their students. Understanding technology adoption, especially social media technology adoption, by teachers and students is particularly important in Nigeria in view of the growing awareness of social media among youths and the vast subscription and penetration of mobile technology in Nigeria [12]. In addition, understanding how teachers, including pre-service teachers, adopt technology will lend support to the successful integration of technology into teaching and learning.

It is my belief that pre-service teachers' adoption of a technology will influence their use of the technology when they get into service and concomitantly influence the younger generation's adoption of the technology. It is against this background that this paper explored the pattern of adoption of social media technology by pre-service teachers. Specifically, this paper reports on the following questions:

- Which social media applications are predominantly used by pre-service teachers?

- What do pre-service teachers use social media for?

- What is the average time pre-service teachers spend on social media daily?

- What are pre-service teachers' perceptions of the usefulness of social media?

- Is there any relationship between the time pre-service teachers spend on social media and their perception of the usefulness of social media?

- Is there any relationship between the pre-service teachers' social media subscriptions and their perception of the usefulness of social media? 
As pointed out by [13] social media research is still emerging and there are a few scholarly guides to provide principles on how to adopt social media. This seems particularly true in education. The goal of this paper is to present empirical evidence of pre-service teachers' adoption of social media and their perceptions regarding its usefulness, in order to contribute to the discourse on technology acceptance and particularly social media adoption by pre-service teachers. In addition, this study contributes to the current dearth of knowledge on the adoption and perceived usefulness of the social media network by pre-service teachers.

Social media and a theoretical background of the study are first discussed. Then the results of the adoption of social media by the pre-service teachers who were participants in the study and their perception of the usefulness of the social media to communicate, socialise and study are provided. This is followed by analyses of the relationships between time spent on social media and perceived usefulness, and between social media subscriptions and perceived usefulness. The paper is concluded by discussing the results and the implications for teaching and learning.

\subsection{Social media}

Social media are web-based platforms that facilitate interaction, and exchange of information [14] they allow users to communicate with people all over world [15] and enable individuals and organisations "to create a profile, add or follow users and receive updates on the posts or activities of users" [16]. Examples of social media platforms include Facebook, WhatsApp, 2go, Twitter and YouTube.

Social media offer many benefits which include (i) making it easy for users to connect with friends and colleagues; (iii) facilitating supportive relationships among people in a group; (ii) promoting a sense of belonging and self-esteem among users; (iv) facilitating the organisation of activities or events; (v) disseminating information to a wider audience; and (vi) enhancement of individual and collective creativity and ideas through development and sharing of intellectual products. In the business sector, social media has been the most transformative information technology innovation [17], significantly influencing how business organisations interact with their customers [18]. Despite these benefits of using the social media, some people associate the social media with a deterioration of traditional social networks and communication skills. Some others believe that the social media networks make students engage in time wasting social interactions that are academically unprofitable to them. Some studies have associated the use of social media with depressive tendencies [19] that may result from the feeling of inadequacy one may experience after observing the positive things in others on the social media sites.

\subsection{Social media and education}

In education, social media networks may present opportunities for deep scholarly engagements as they promote collaborative learning among students, metacognition and self-efficacy [20]. Through collaboration with others, students can achieve higher level thinking skills. Social media may provide relevant data, which students can 
apply to improve research on assignments and projects. Students can also access tutorials on topics of interest to them online.

Although students' use of social media and their effect on the academic performance of the students have not been extensively researched, there seems to be some support that the social media may present opportunities to enrich teaching and learning due to the vast amount of information available through the social media network. Social media can help students create and manage study groups from which the students can tap from the collective knowledge of their groups to make studying more efficient for every member of the group [21]. This is in accord with the social capital theory (Bourdieu, in [22]) which proposes that a person's participation in a particular social group will provide some benefit to the person.

[23], in their study on social media and student outcomes in vocational education and training in Australia, found that using social media in their studies encourage greater involvement in the learning process in some students and may result in higher student completions. In an investigation into the effect of Twitter on students' involvement and performance, [8] found that the use of Twitter led to increased involvement by the students as well as improved semester performance. Hence, the authors stated that Twitter could be a useful educational aid to assist students and faculty members to take part and play a more active role.

[24] explored students' view of using Facebook as a learning management system and found that the students believe that Facebook could be useful to their studies. In a study that explored college students' perceptions of what impact social media had on their educational efforts in Guwahati city in India, [25] found that while the majority of the students believed that social media may have a positive impact on their education; the students also perceived that social media may hamper educational efforts by reducing study hours which may occur when one gets involved in social media chatting. The participants in the study also indicated that exposure to cyber bullying and privacy concerns may have an adverse impact on the mental state of the students which can adversely influence the academic environment. In Saudi Arabia, [26] investigated science teachers' and students' use and perception of the impacts of social media on the teaching and learning of science courses and found that the teachers and students believed that social media could enhance their teaching and learning and were willing to adopt social media for this purpose. However, the teachers and students use social media mainly for socializing and not for education.

On the contrary, some scholars do not believe that social media are beneficial to students learning. In a study on undergraduate students' perception and use of Facebook, [27] used a sample of two hundred undergraduate students from two universities in South Africa and found that though $88 \%$ of the students use Facebook for socialisation and communication but $50 \%$ of the students did not perceive Facebook as a useful tool for studies. Likewise, [28] do not believe that social media are useful to students' work. These authors are of the view that social media impact negatively on students' education because social media networks distract students from their studies.

Using a sample of 340 students from a state university in the United States, [29] studied the effect that the time spent by students on social media had on their course tests and average marks obtained and found a small but significant negative relation- 
ship $(\mathrm{r}=-.119, \mathrm{p}=.048)$ between time spent on social media and the student's performance. Similarly, [7] also reported a negative relationship between students' social media use and their average marks obtained. They found significant mean differences between the average grade scores of users $(M=3.06)$ and nonusers $(M=3.82)$, and some of the participants reported that social media had a distractive effect on their studies.

[30] examined the relationship between the pattern of Facebook use by students, their preparations for class and their average grades, using a sample of 1839 college students. They found that time spent on Facebook correlated negatively with students' average grade point, and that utilising Facebook mainly for collecting and sharing information predicted a positive outcome while using Facebook to for socialising predicted a negative outcome in respect of students' academic performance.

\section{Theoretical Background}

Many theories have been proposed to explain peoples' acceptance of technology and their intention to use technology. The theories, among others, include Social constructivist theory (based on the work of Vygotsky, 1980), Theory of Planned Behaviour [31] and the Technology Acceptance Model [32]. These three theories are form the theoretical framework for this study.

\subsection{Social constructivist theory}

Social constructivist theory advances that knowledge is created by social relationships and interactions [33]. Hence, "human development is socially situated and knowledge is constructed through interaction with others" [34, p. 184]. The theory stresses that the context is important in the construction of knowledge. Social constructivists believe that learning is a social process that occurs when individuals take part in social activities. The social constructivists believe that our world is shaped by the social interactions - dialogues and discourses we have with each other [6]. Hence, a students' learning experience is shaped by the discourse the students engages in with others. To the social constructivists, our understanding of the world arises from our own shared construction of the world [6]. We all belong to various communities and the communities we belong to, to every large extend, influence our experiences and consequently our learning. According to [35], "the community creates the social fabric of learning" (p28). The users of the social media build communities through their interactions and discourses. The interactions allow them to make sense of their experiences and create new knowledge, giving credence to their understanding of the world. Our understanding of the world - our beliefs and ethical norms, are products of our interactions in communities over time. As [6] opined, our daily social interactions and relationships are the source of what is true to us. Going by this view, one can say that one's social environment or community can change ones knowledge or way of thinking. According to social constructivists, learning environments that promote students' active participation, interaction and dialogue provide them with a chance to 
involve themselves in a process of knowledge construction [36]. This means that teachers can improve teaching by designing a supportive learning environment that encourages their students to interact socially with other students and the teacher.

Interactions in communities are mediated by tools; the nature of the tools according to social constructivists (e.g. Vygotsky 1980) will impact on the interaction among the people in the communities. The tools can change one's way of interaction within the community. Hence using the social media in a learning community can change how students learn and how much they learn. Social media provide the framework for interactivity that includes dialogue, discussion, and debate and as such can lead to the social construction of meaning.

\subsection{Technology acceptance model (TAM).}

TAM, according to [32] is an information system theory which proposes that people will likely use technology if they perceive the technology useful for their needs and easy to use. That is, two main factors serve as predictors of acceptability of a technology (technology acceptance intention). The factors are Perceived Usefulness and Perceived Ease of Use. Perceived Usefulness is the degree to which a person believed that using a system improved his/her performance and Perceived Ease of Use is the degree to which a person believed that using a system was easy. TAM was first proposed by [37] and has since been applied in Information Systems research related to acceptance of various technologies in a range of fields [38]. In education, TAM has been widely applied to explain educators' and students' acceptance of many education technologies [39], [40]. Many researchers, to cater for some latent variables in the original TAM, have revised the first version of TAM proposed by Davis [40], [41]. The revisions are not of interest in this paper as the focus of the paper is not on the relationship between the variables of TAM but the interest of the paper lies in the degree to which the social media technology is accepted by the pre-service teachers and their perception of the usefulness of the technology.

\subsection{The theory of planned behaviour}

The theory of planned behaviour [31] contends that the drivers behind individual behaviour are behaviour intentions, and behaviour intentions are determined by an individual's attitude towards behaviour, subjective norms, and perceived behavioural control.

Attitude towards behaviour is the individual's disposition or feelings about performing the behaviour. In the case of this study, it is the extent of the pre-service teachers' favourable or unfavourable disposition to the use of social media. Attitude towards behaviour is what [37] refers to as the perceived usefulness in TAM. Attitude has been found in some studies to be a strong predictor of intention [5]. A subjective norm is created by the individual's perception that people seen as important to the individual would perform the behaviour in question. It pertains to an individual's perception of the social environment in which the behaviour occurs. The opinions of others (for example, faculty members and other students) important to a student are 
significant in determining the student's intention to use social media. Perceived behaviour control is an individual's perception of the difficulty or ease of performing the behaviour, according to [37]. Perceived behaviour control does not indicate the likelihood that performing the behaviour will produce a given outcome, but refers to an individual's degree of control over performance of behaviour [5].

\section{$3 \quad$ Methodology}

\subsection{Design and participants}

A cross-sectional survey research design was used as the mode of inquiry for this study. A cross-sectional survey entails collecting data at one point in time or over a short period in order to make inferences about a population [42]. The participants were 388 pre-service teachers who enrolled for undergraduate teacher education programmes in one tertiary education institutions in Nigeria. The sample was conveniently chosen because they gave their consent to participate in the study. They were 128 $(33 \%)$ males and $260(67 \%)$ females whose ages ranged between sixteen years and thirty years $(M=21$ years; $S D=3)$. Data was collected using a questionnaire which consisted of both closed and open ended questions. It elicited information on the students' knowledge of social media, their use of it and their perception of the usefulness of social media.

The questions were kept brief and worded as broadly as possible to invite open and sincere responses from the participants. A total of 404 questionnaires were received back from the students but after data cleansing only 388 of the questionnaires were found usable. It should be noted here that the 388 participants did not respond to all the items in the instruments, hence there were some discrepancies in the total number of respondents per item.

\subsection{Data analysis and result}

Qualitative content analysis was applied on the data collected via the open ended questions to identify themes in the participants' responses after which descriptive statistics were used to represent the frequency and percentage of participants whose responses corresponded to the themes identified in each question. In addition, a Spearman's correlation analysis at .05 alpha level was conducted to investigate the relationship between time spent on social media and the perceived usefulness of social media and also between social media subscriptions and the perceived usefulness of social media variables. 


\section{$4 \quad$ Results}

\subsection{Adoption of social media}

The responses provided by the students indicate that they are registered users of social media networks. Three hundred and sixty (360) participants representing 93\% of the participants indicated that they use social media while 28 students $(7 \%)$ indicated that they do not use social media. Facebook, WhatsApp, 2go, and Twitter were the predominant social media used by the pre-service teachers as shown by the number of registered users of the media in Table 1, with Facebook being the most popular social media application among the pre-service teachers.

Table 1. Social media accounts

\begin{tabular}{|l|c|c|}
\hline \multicolumn{1}{|c|}{ Medium } & Registered users & Percent \\
\hline Facebook & 305 & 78.6 \\
\hline WhatsApp & 224 & 57.7 \\
\hline Twitter & 93 & 24 \\
\hline BlackBerry Messenger & 66 & 17 \\
\hline 2go & 111 & 28.6 \\
\hline Badoo & 15 & 3.8 \\
\hline Instagram & 10 & 2.6 \\
\hline YouTube & 6 & 1.5 \\
\hline Eskimi & 32 & 8.2 \\
\hline
\end{tabular}

Among the participants, 94 (24\%) have only one social medium account subscription (for example Facebook or WhatsApp only), 75 (19\%) have two account subscriptions (for example Facebook and 2go) while 109 (28\%) have three account subscriptions. In addition, $71(18 \%)$ and 14(4\%) have four and five account subscriptions respectively as shown in Table 2 .

Table 2. Frequency of social media account subscriptions

\begin{tabular}{|c|c|c|}
\hline No of Accounts & No of student users & Percentage \\
\hline 1 & 94 & 24 \\
\hline 2 & 75 & 19 \\
\hline 3 & 109 & 28 \\
\hline 4 & 71 & 18 \\
\hline 5 & 14 & 4 \\
\hline
\end{tabular}

\subsection{Time spent on social media}

Regarding the time the participants spend on social media, the participants were asked the average time they spend on social media a day. It was found that most of the students (310 representing 80\%) spend an average of at least one hour on social media a day, $196(50 \%)$ spend two hours or more on social media on average every day and 
$101(25 \%)$ spend an average of three hours or more on social media daily. Generally, the students spend an average of 2.3 hours on social media daily.

\subsection{Purpose of use of social media}

The participants were asked the purpose for which they have adopted social media. The number of students who have adopted social media and the purpose for which they have adopted the media are shown in Figure 1. The Figure shows that the students use social media mainly for socialising (310) and communication (323) rather than for studies (193), while other uses include getting information (163), business (like searching for jobs) (75) and entertainment (45).

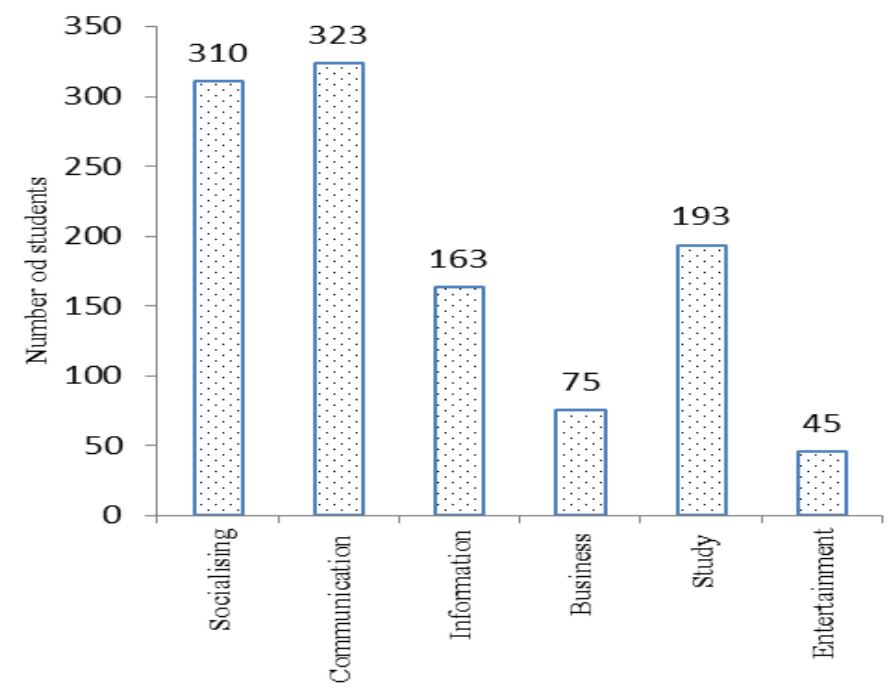

Fig. 1. Pattern of social media use

\subsection{Perceived usefulness of social media}

The focus here was to find out how useful the pre-service teachers perceived social media for communication, studies and for social activities (socialising). They were asked to rate how useful (valuable) they found social media for communication, socialising and studies using the scale Not Useful (Not valuable), Slightly Useful (Slightly valuable), Useful (valuable) and Very Useful (Very valuable). The pattern of their responses (Figure 2) shows that the majority of them perceive social media useful for studies, communication and social activities but especially for studies. 


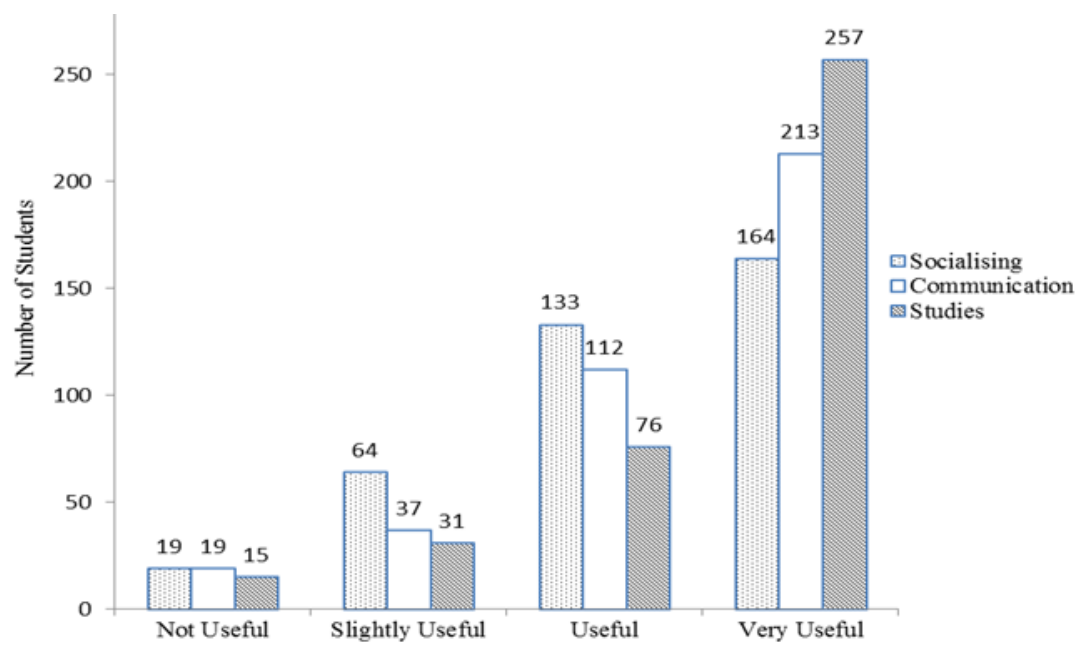

Fig. 2. Students' perceived usefulness of Social media

\subsection{Relationship between the time spent on social media and its perceived usefulness}

The Spearman's rank-order correlation coefficient was used to measure the strength of the relationship between time spent on, and the perceived usefulness of social media for socialising, communication and study. Table 3 displays the result of the correlation analysis.

Table 3. Table 3: Relationship between time spent and perceived usefulness of social media

\begin{tabular}{|l|l|}
\hline & $\boldsymbol{\rho}$ \\
\hline Socialising & $.135^{*}$ \\
\hline Communication & .104 \\
\hline Study & $.124^{*}$ \\
\hline
\end{tabular}

*. Correlation is significant at the 0.05 level (2-tailed).

The relationship between time spent on social media and the perceived usefulness of social media for socialising was found to be statistically significant, $r(309)=+.135$, $\mathrm{p}<.05$. This indicates that the time the participants spent on social media was related to their perceived usefulness of social media for socialising. Similarly, the correlation between time spent on social media and the perceived usefulness of social media for study was found to be statistically significant, $\mathrm{r}(309)=+.124, \mathrm{p}<.05$, indicating that the time spent on social media was related to perceived usefulness of social media for study. However, the relationship between time spent on social media and the perceived usefulness of social media for communication was not found to be statistically significant, $r(310)=+.104, p>.05$. Although the relationship was positive, the result indicates that time spent on social media was unrelated to perceived usefulness of social media for communication. 


\subsection{Relationship between social media account subscription and perceived usefulness}

To measure strength of relationship between social media subscriptions and the perceived usefulness of social media for socialising, communication and study, Spearman's rank-order correlation analysis was carried out. The result is displayed in Table 4.

Table 4. Relationship between subscriptions and perceived usefulness of social media

\begin{tabular}{|l|c|}
\hline & $\boldsymbol{\rho}$ \\
\hline Socialising & $.149^{* *}$ \\
\hline Communication & $.107^{*}$ \\
\hline Study & .069 \\
\hline
\end{tabular}

**. Correlation is significant at the 0.01 level (2-tailed).

*. Correlation is significant at the 0.05 level (2-tailed).

As indicated in Table 4, the relationship between social media account subscriptions and perceived usefulness of social media for socialising was found to be statistically significant, $\mathrm{r}(377)=+.149, \mathrm{p}<.05$. This indicates that social media account subscriptions were related to perceived usefulness of social media for socialising. Similarly, the correlation between social media account subscriptions and perceived usefulness of social media for communication was found to be statistically significant, $\mathrm{r}(379)=+.107, \mathrm{p}<.05$. This implies that social media account subscriptions were related to perceived usefulness of social media for communication. Nevertheless, the relationship between social media subscriptions and perceived usefulness of social media for study was not found to be statistically significant, $r(377)=+.069, \mathrm{p}>.05$. Although the association is positive the results indicate that social media subscription was unrelated to perceived usefulness of social media for study.

\section{Discussion}

The objective of the study was to explore to what extend pre-service teachers from a college of education in Nigeria adopted social media technology in their teaching and what they perceived the benefits to be. The study found that Facebook and WhatsApp were the social media most frequently used by the pre-service teachers with Facebook being the most popular application adopted by them. It was found that the participants adopted social media mainly as tools for socialising and communication. In addition, it was found that half of the pre-service teachers spend at least two hours a day on social media and the majority (69\%) have more than one social media account subscription.

The predominance of Facebook use among the participants was not found surprising because Facebook is the largest and most popular social media platform in the world [43], [44] and it has been popularly adopted by individuals and organisations [45]. In accordance with the theory of planned behaviour that individual's behaviour intentions are in part determined by the individual's perception of the social environ- 
ment surrounding the behaviour, the wide range of adoption of Facebook will likely affect its adoption by students. The same could be said of WhatsApp which has become widely used by both individuals and organisations [46]. Also, the high rate of use of WhatsApp by the participants could be accounted for by the cheap cost of sending WhatsApp messages (tests, photos, audios and videos) and ease of use.

These findings corroborate the findings of [27] in South Africa that there is a high adoption of social media among undergraduate students. The results also agree with the results of [26] in Saudi Arabia that social media are significantly adopted by teachers and students for communication and not for education. The findings also confirm the findings of some other studies (e.g. [19], [47]) that social media have emerged as a highly useful communication technology among students.

Furthermore, it was found that the participants perceived social media useful for studies, communication and social activities as was also found by [26] and [25]. This study confirms that students can perceive the educational usefulness of social media even though many of them may not know how best to utilise it to enhance their learning experiences. In line with the Technology Acceptance Model [32], the pre-service teachers' high perceived usefulness of social media for study implies that they will like to use it for study purposes if given the motivation.

The relationships between the time spent on social media and perceived usefulness of social media (i) for socialising and (ii) for study were found to be positive and statistically significant. Similarly, the relationships between social media subscriptions, and perceived usefulness of social media (i) for socialising and (ii) for communication were found to be positive and statistically significant.

The high adoption of social media by the pre-service teachers found in this study and its high perceived usefulness indicate that, if the students were to use social media as an educational aid, they would likely become more involved in learning and become more knowledgeable and better trained teachers. To achieve this objective, course materials should be made available through the social media while academic discussion forums and online tutorial classes should be created by faculty members. Students should then be encouraged to join and participate in the collaboration facilities and on-line tuition opportunities.

\section{Conclusion}

The objective of the research was to augment an area of research still not well researched. Specifically, the study aimed to explore the adoption and perceived benefits of social media technology by pre-service teachers from two tertiary education institutions in Nigeria. This study revealed that social media is deeply used among the preservice teachers and there is optimism among them regarding the usefulness of social media for learning. However, the students embrace social media more as a tool for social connection than for learning.

Accordingly, an important takeaway from the findings of this study is that preservice teachers use social media and the affordances of the media may be used to facilitate teaching and learning. Social Media may represent powerful transformative 
tools in education, not just as a communication tool but also an important tool for enhancing teaching and learning.

\section{$7 \quad$ Recommendations}

As "education likes to explore emerging technologies as new or improved tools to enhance instruction and learning" [47, p. A66], the affordances of social media should be utilised to enhance students' academic learning experiences. That being the case, members of faculty will of necessity need to adjust their educational philosophy and practices to meet the demands and challenges of the 21 st century students. Hence, there is a need for academics to explore the social media in educational settings in order to learn and leverage the pedagogical and didactical potentials of the social media. This will possibly arouse their desire to drive the move towards the incorporation of the social media in education.

For faculties to be able to integrate social media with teaching, they may need to be trained on how the social media platform could be effectively utilised in education. In addition, institutions of learning will need to put in place the necessary infrastructure (e.g. high-speed wireless communication systems) to support social media's incorporation into teaching and learning. Also, the institutions will need to develop strategies of how social media might be used to boost teaching and learning.

Furthermore, it is recommended here that students should be supported to acquire skills to use the collaborative learning capabilities of the social media. This may be realised by including training courses on basic computer and social media skills as part of the general foundation universities/colleges courses.

\section{$8 \quad$ Limitations}

A limitation of this study is that it was based on self-report. There is the possibility that some participants did not provide accurate information. Similarly, the questions regarding social media use did not ask about device type and ownership. Device type and ownership could have influenced the use pattern. In addition, the study did not explore access to a regular power supply, which constitutes a major issue in the country and could have affected the participants' use of their social media devices. Future studies may take these issues into consideration.

\section{References}

[1] H. A. Efe, "The relation between science student teachers' educational use of web 2.0 technologies and their computer self-efficacy," Journal of Baltic Science Education, vol. 14, no. 1, p. 142-154, 2015.

[2] D.Glušac, V. Makitan , D. Karuvic and D. Radosav, “Adolescents' informal computer usage and their expectations of ICT in teaching-case study: Serbia," Computers and Education, vol. 81, p. 133-142, 2015. https://doi.org/10.1016/j.compedu.2014.10.006 
[3] P.Sendurur, E. Sendurur and R. Yilmaz, "Examination of the social network sites usage patterns of pre-service teachers," Computers in Human Behavior, vol. 51, p. 188-194, 2015. https://doi.org/10.1016/j.chb.2015.04.052

[4] P. L. Mofokeng and A. Mji, "Teaching mathematics and science using computers: How prepared are South African teachers to do this?," Procedia Social and Behavioral Sciences, vol. 2, no. 2, p. 1610-1614, 2010. https://doi.org/10.1016/j.sbspro.2010.03.245

[5] J. Cheon, S. Lee, S. M. Crooks and J. Song, "An investigation of mobile learning readiness in higher education based on the theory of planned behavior," Computers \& Education, vol. 59, no. 3, p. 1054-1064, 2012. https://doi.org/10.1016/j.compedu.2012.04.015

[6] C. N. Gunawardena, D. S. Hermans, C. Richmond , M. Bohley and R. Tuttle, "A theoretical framework for building online communities of practice with social networking tools," Education Media International, vol. 46, no. 1, p. 3-16, 2009. https://doi.org/10.1080/09523980802588626

[7] P. A. Kirschner and A. C. Karpinski, "Facebook ${ }^{\circledR}$ and academic performance," Computers in Human Behavior, vol. 6, no. 6, p. 1237-1245, 2010. https://doi.org/10.1016/j.chb.2010.03.024

[8] R. Junco, G. Heiberger and E. Loken, "The effect of Twitter on college student engagement and grades," Journal of Computer Assisted Learning, vol. 27, no. 2, p. 119-132, 2011. https://doi.org/10.1111/j.1365-2729.2010.00387.x

[9] T. A. Cullen and B. A. Greene, "Preservice teachers' beliefs, attitudes, and motivation about technology integration," The Journal of Educational Computing Research, pp. 29-47, 2011. https://doi.org/10.2190/ec.45.1.b

[10] T. Teo and J. Noyes, "An assessment of the influence of perceived enjoyment and attitude on the intention to use technology among pre-service teachers: A structural equation modelling approach," Computers \& Education, vol. 57, no. 2, p. 1645-1653, 2011. https://doi.org/10.1016/j.compedu.2011.03.002

[11] D. Ifenthaler and V. Schweinbenz, "Students' Acceptance of Tablet PCs in the Classroom," Journal of Research on Technology in Education, vol. 48, no. 4, pp. 306-321, 2016. https://doi.org/10.1080/15391523.2016.1215172

[12] Vanguard, "Nigeria becoming mobile-first country with $162 \mathrm{~m}$ subscribers-Jumia," 15 March 2018. [Online]. Available: https://www.vanguardngr.com/2018/03/nigeriabecoming-mobile-first-country-162m-subscribers-84-penetration-rate-jumia. [Accessed 28 August 2018].

[13] L. A. McFarland and R. E. Ployhart, "Social media: A contextual framework to guide research and practice,” Journal of Applied Psychology, vol. 100, no. 6, pp. 1653-1677, 2015. https://doi.org/10.1037/a0039244

[14] J. Surowiecki, The Wisdom of Crowds, New York: Anchor Books, 2005.

[15] D. L. Williams, V. L. Crittenden, T. Keo and P. McCarty, "The use of social media: an exploratory study of uses among digital natives," Journal of Public Affairs, vol. 12, no. 2, pp. 127-136, 2012. https://doi.org/10.1002/pa.1414

[16] D. M. Boyd and N. B. Ellison, "Social network sites: Definition, history, and scholarship," Journal of Computer-Mediated Communication, vol. 13, no. 1, p. 210-230, 2007. https://doi.org/10.1111/j.1083-6101.2007.00393.x

[17] S. Aral, C. Dellarocas and D. Godes, "Introduction to the special issue - social media and business transformation: A framework for research," Information Systems Research, vol. 24, no. 1, pp. 3-13, 2013. https://doi.org/10.1287/isre.1120.0470

[18] R. Agnihotri, R. Dingus and M. Y. Hu, "Social media: Influencing customer satisfaction in B2B sales," Industrial Marketing Management, vol. 53, pp. 172-180, 2016. https://doi.org/10.1016/j.indmarman.2015.09.003 
[19] J. A. Datu, J. P. Valdez and N. Datu, "Does Facebooking make us sad? Hunting relationship between Facebook use and depression among Filipino adolescents," International Journal of Research Studies in Educational Technology, vol. 1, no. 2, p. 83-91, 2012. https://doi.org/10.5861/ijrset.2012.202

[20] N. Dabbagh and A. Kitsantas, "Personal learning environments, social media, and selfregulated learning: A natural formula for connecting formal and informal learning," The Internet \& Higher Education, vol. 15, no. 1, p. 3-8, 2012. https://doi.org/10.1016/j.iheduc.2011.06.002

[21] C. Greenhow and C. Lewin, "Social media and education: Reconceptualizing the boundaries of formal and informal learning," Learning Media and Technology, vol. 41, no. 1, pp. 6-30, 2015. https://doi.org/10.1080/17439884.2015.1064954

[22] J. G. Richardson, Ed., Handbook of Theory and Research for the Sociology of Education, New York: Greenwood Press, 1986.

[23] V. Callan and M. Johnston, Social media and student outcomes: teacher, student and employer views, Adelaide Australia: NCVER, 2017.

[24] Q. Wang, H. L. Woo, C. L. Quek, Y. Yang and M. Liu, "Using the Facebook group as a learning management system: An exploratory study," British Journal of Educational Technology, vol. 43, no. 3, pp. 428-438, 2012. https://doi.org/10.1111/j.14678535.2011.01195.x

[25] P. D. Deka, "A Study on Impact of Social Media on Educational Efforts in Guwahati City, Assam," International Journal of Advanced Research in Education Technology, vol. 2, no. 3, pp. 90-94, 2015.

[26] S. A. Alabdulkareem, "Exploring the Use and the Impacts of Social Media on Teaching and Learning Science in Saudi," Procedia - Social and Behavioral Sciences, vol. 182, pp. 213-224, 2015. https://doi.org/10.1016/j.sbspro.2015.04.758

[27] U. I. Ogbonnaya and A. Mji, "Undergraduate students' use of Facebook in South Africa," in Proceedings of Multidisciplinary Academic Conference on Education, Teaching and Learning, Prague, 2015.

[28] W. Tariq, M. Mehboob, M. A. Khan and F. Ullah, "The impact of social media and social networks on education and students of Pakistan," International Journal of Computer Science Issues, vol. 9, no. 4, pp. 407-411, 2012.

[29] J. A. Paul, H. M. Baker and J. D. Cochran, "Effect of online social networking on student academic performance," Computers in Human Behavior, vol. 28, no. 6, p. 2117-2127, 2012. https://doi.org/10.1016/j.chb.2012.06.016

[30] R. Junco, "Too much face and not enough books: The relationship between multiple indices of Facebook use and academic performance," Computers in Human Behavior, vol. 28, no. 1, pp. 187-198, 2012. https://doi.org/10.1016/j.chb.2011.08.026

[31] I. Ajzen, "The theory of planned behavior," Organizational Behavior and Human Decision Processes, vol. 50, no. 2, p. 179-211, 1991. https://doi.org/10.1016/0749-5978(91)90020-t

[32] V. Venkatesh and F. D. Davis, "A Theoretical Extension of the Technology Acceptance Model: Four Longitudinal Field Studies," Management Science, vol. 46, no. 2, pp. 186204, 2000. https://doi.org/10.1287/mnsc.46.2.186.11926

[33] L. S. Vygotsky, Mind in society: The development of higher psychological processes, Cambridge, MA: Harvard University Press, 1980.

[34] J. McKinley, "Critical Argument and Writer Identity: Social Constructivism as a Theoretical Framework for EFL Academic Writing," Critical Inquiry in Language Studies, vol. 12, no. 3, p. 184-207, 2015. https://doi.org/10.1080/15427587.2015.1060558

[35] E. Wenger, R. McDermott and W. Snyder, A guide to managing knowledge: Cultivating communities of practice, Boston: Harvard Business School Press, 2002. 
[36] D. Jonassen, M. Davison, M. Collins, J. Campbell and B. B. Haag, "Constructivism and computer mediated communication in distance education," The American Journal of Distance Education, vol. 9, no. 2, p. 7-26, 1995. https://doi.org/10.1080/08923649509526885

[37] F. Davis, "Perceived usefulness, perceived ease of use, and user acceptance of information technology," MIS Quarterly, vol. 13, no. 3, p. 319-339, 1989. https://doi.org/10.2307/249008

[38] P. Surendran, "Technology Acceptance Model: A Survey of Literature," International Journal of Business and Social Research, vol. 2, no. 4, p. 175-178, 2012.

[39] L. Goosen and J. Vorster, "Beyond familiar territories towards educational technologies: framework for higher education institutions and e-schools partnerships," in Proceedings of South Africa International Conference on Educational Technologies, Pretoria, 2018.

[40] U. A. Yucel and Y. Gulbahar, "Technology Acceptance Model: A Review of the Prior Predictors," Journal of the Faculty of Educational Sciences, vol. 46, no. 1, p. 89-109, 2013.

[41] M. Y. Chuttur, "Overview of the technology acceptance model: Origins, developments and future directions," Working Papers on Information Systems, vol. 9, no. 37, p. 9-37, 2009.

[42] J. W. Creswell, Educational research: Planning, conducting, and evaluating quantitative and qualitative research, 5th ed., Boston, MA: Pearson, 2015.

[43] R. Gadekar and P. Krishnatray, "Gratifications of Facebook: A Literature Review," Online Journal of Communication and Media Technologies, vol. 7, no. 1, pp. 87-103, 2017.

[44] C. Montag, A. Markowetz, K. Blaszkiewicz, I. Andone, B. Lachmann, R. Sariyska, B. Trendafilov, M. Eibes, J. Kolb, M. Reuter, B. Weber and S. Markett, "Facebook usage on smartphones and gray matter volume of the nucleus accumbens," Behavioural Brain Research, vol. 329, pp. 221-228, 2017. https://doi.org/10.1016/j.bbr.2017.04.035

[45] W. Świeczak, "The impact of modern technology on changing marketing actions in organisations. Marketing 4.0," Marketing of Scientific and Research Organizations, vol. 26, no. 4, pp. 161-186, 2017.

[46] S. Z. Ahmad , A. R. AbuBakar and N. Ahmad, "Social media adoption and its impact on firm performance: the case of the UAE," International Journal of Entrepreneurial Behavior \& Research, 2018.

[47] P. A. Tess, "The role of social media in higher education classes (real and virtual) - A literature review," Computers in Human Behavior, vol. 29, no. 5, pp. A60-A68, 2013. https://doi.org/10.1016/j.chb.2012.12.032

\section{Authors}

Ugorji I. Ogbonnaya is a lecturer in mathematics education at University of Pretoria, South Africa. His research interest includes the use of technology in teaching and learning

Article submitted 2019-02-09. Resubmitted 2019-03-15. Final acceptance 2019-03-25. Final version published as submitted by the authors 